\title{
Global Trends in Plant Genomics Research to Improve Crop Productivity at PAG XXIV Conference
}

\author{
Shadi Rahimi ${ }^{1}$, Kwon-Kyoo Kang ${ }^{2 *}$, Yong-Gu Cho ${ }^{1 *}$ \\ ${ }^{1}$ Department of Crop Science, Chungbuk National University, Cheongju 28644, Korea \\ ${ }^{2}$ Department of Horticulture, Hankyong National University, Anseong 17579, Korea
}

\begin{abstract}
Increasing demand for food commodities and energy supply highlight the necessity to further improve crop productivity. At the Plant and Animal Genome Conference (PAG XXIV), recent developments and future plans for genomics research of plants and animals were presented. PAG XXIV provided a forum to explore crop genomes with the aim of providing new opportunities for crop breeding and the foundation for functional genomic studies to improve agriculture production and help feed the growing population. Genetic diversity and population structure studies of crops have allowed us to explore alleles related to different characteristics important for plant breeding. Several useful databases were introduced in PAG XXIV. They were developed to integrate a growing set of commonly used data types and analysis tools with new capabilities for visualization, exploration, and predictive analysis. This review highlights the global trends in plant genomics presented at PAG XXIV by focusing on crop productivity.
\end{abstract}

Keywords PAG XXIV, Plant, Genomics, Biomass, Grain yield, Abiotic stress

\section{INTRODUCTION}

Global human population is expected to exceed 9.6 billion by 2055 . To meet the increasing demand for food commodities, crop productivity in sustainable agricultural systems must be improved considerably to face changing climates and increasing biotic and abiotic stresses. Achieving this will require holistic and systematic approaches by combining a wide range of disciplines including agronomy, physiology, genomics, genetics, breeding, physics, and modeling. The key to successful breeding programs for crop improvement is to understand the extent of genetic variations among crops. Advances in sequencing and data analysis techniques have greatly improved our ability to dissect and mine genomes for specific genes underlying significant traits and allelic variations.

Environmental stresses are the most serious factors limiting the productivity of agricultural crops. Recent studies have linked increased frequency of severe abiotic stress events to global warming, emphasizing the urgent need to develop crops with enhanced tolerance to abiotic stresses. Abiotic stress tolerance is particularly important for crop productions because they must be grown under low-input conditions to maximize net carbon ratio or on marginal land to minimize competition with food crops (Sade et al. 2016).

The Plant and Animal Genome Conference (PAG XXIV) provided a forum on recent developments and future plans for plant and animal genome projects. Consisting of technical presentations, poster sessions, exhibits and workshops, the conference provided an excellent opportunity to exchange ideas and applications on this internationally important genome project. PAG XXIV opened avenues for understanding aspects of plant biology such as plant responses to environmental stresses, plant-pathogen interactions, and trait improvement. This review summarized the new trends in plant genomics with focus on crop

Received February 1, 2016; Revised February 5, 2016; Accepted February 11, 2016; Published February 28,2016

*Corresponding authors Kwon-Kyoo Kang, kykang@hknu.ac.kr, Tel: +82-31-670-5104, Fax: +82-31-670-5109

Yong-Gu Cho, ygcho@cbnu.ac.kr, Tel: +82-43-261-2514, Fax: +82-43-273-2242

*These authors contributed equally to this paper as co-corresponding authors. 
Table 1. The databases were introduced in PAG XXIV.

\begin{tabular}{|c|c|c|c|c|}
\hline Name & Source & Website & Description & Reference \\
\hline $\begin{array}{l}\text { Plant Reactome } \\
\text { database }\end{array}$ & Model and crop plant species & $\begin{array}{l}\text { http://plantreactome. } \\
\text { gramene.org/ }\end{array}$ & $\begin{array}{l}\text { Gene products, small molecules and } \\
\text { macromolecular interactions into reactions and } \\
\text { pathways in context of their subcellular location }\end{array}$ & $\begin{array}{l}\text { Jaiswal } \\
\text { et al. } 2016 \mathrm{~b}\end{array}$ \\
\hline KBase & Microbes, fungal, and plant genomes & http://kbase.us & $\begin{array}{l}\text { Metabolic models of specific microbes, fungal, } \\
\text { and plant genomes and their interactions, to } \\
\text { understand plant microbial and mycorrhizal } \\
\text { interactions }\end{array}$ & $\begin{array}{l}\text { Kumari } \\
\text { et al. } 2016\end{array}$ \\
\hline $\begin{array}{l}\text { Plant Wikipathways } \\
\text { portal }\end{array}$ & Plants & $\begin{array}{l}\text { http://www.wikipath } \\
\text { ways.org/index.php/ } \\
\text { Portal:Plants }\end{array}$ & Rice stress-response gene-network & $\begin{array}{l}\text { Naithani } \\
\text { et al. } \\
\text { 2016a }\end{array}$ \\
\hline $\begin{array}{l}\text { DNA polymorphism } \\
\text { annotation database } \\
\text { (DNApod) }\end{array}$ & Plants and crops & $\begin{array}{l}\text { http://tga.nig.ac.jp/dn } \\
\text { apod/ }\end{array}$ & $\begin{array}{l}\text { Integration of SRA-driven genotypic data and } \\
\text { public phenotypic data }\end{array}$ & $\begin{array}{l}\text { Mochizuki } \\
\text { et al. } 2016\end{array}$ \\
\hline $\begin{array}{l}\text { DNA Data Bank of } \\
\text { Japan }\end{array}$ & & $\begin{array}{l}\text { http://www.ddbj.nig. } \\
\text { ac.jp }\end{array}$ & $\begin{array}{l}\text { Public data center of nucleotide sequences } \\
\text { established at the National Institute of Genetics }\end{array}$ & $\begin{array}{l}\text { Kodama } \\
\text { et al. } 2016\end{array}$ \\
\hline Araport & Arabidopsis & $\begin{array}{l}\text { https://www.araport.o } \\
\text { rg }\end{array}$ & $\begin{array}{l}\text { Access to a new generation web-based data } \\
\text { platform }\end{array}$ & $\begin{array}{l}\text { Chan et al. } \\
2016\end{array}$ \\
\hline Ensembl Genomes & $\begin{array}{l}\text { Farm animals and crop plants, from pests, } \\
\text { pathogens and pollinators and symbionts }\end{array}$ & $\begin{array}{l}\text { http://ensemblgenom } \\
\text { es.org }\end{array}$ & $\begin{array}{l}\text { Genome-scale data, covering bacteria, protists, } \\
\text { fungi, plants and invertebrate metazoa, } \\
\text { supplementing the coverage of vertebrate } \\
\text { species }\end{array}$ & $\begin{array}{l}\text { Kersey } \\
2016\end{array}$ \\
\hline $\begin{array}{l}\text { Plant Genome } \\
\text { DataBase Japan }\end{array}$ & Plants & http://pgdbj.jp/en/ & $\begin{array}{l}\text { Access information extracted from many plant } \\
\text { genome-related databases }\end{array}$ & $\begin{array}{l}\text { Ichihara } \\
\text { et al. } 2016\end{array}$ \\
\hline HRGRN & Arabidopsis & $\begin{array}{l}\text { http://plantgrn.noble. } \\
\text { org/hrgrn/ }\end{array}$ & $\begin{array}{l}\text { Model and decipher Arabidopsis signaling } \\
\text { transduction, metabolism and gene regulation } \\
\text { networks using graph theory }\end{array}$ & $\begin{array}{l}\text { Dai and } \\
\text { Zhao } 2016\end{array}$ \\
\hline PeanutBase & Peanut & http://peanutbase.org & $\begin{array}{l}\text { Genome browsers, genetic map viewers, } \\
\text { sequence search tools, and a database of traits } \\
\text { and QTLs }\end{array}$ & $\begin{array}{l}\text { Cannon } \\
\text { et al. } 2016\end{array}$ \\
\hline $\begin{array}{l}\text { Cool Season Food } \\
\text { Legume Genome } \\
\text { Database }\end{array}$ & Pea, Lentil, Faba Bean and Chickpea & $\begin{array}{l}\text { http://www.coolseaso } \\
\text { nfoodlegume.org }\end{array}$ & $\begin{array}{l}\text { Genetic maps, molecular markers, and QTL } \\
\text { data }\end{array}$ & $\begin{array}{l}\text { Humann } \\
\text { et al. } 2016\end{array}$ \\
\hline LegumeIP & Legume & $\begin{array}{l}\text { http://plantgrn.noble. } \\
\text { org/LegumeIP/ }\end{array}$ & $\begin{array}{l}\text { A web-based comparative genomics and gene } \\
\text { expression atlas platform that integrates } \\
\text { large-scale genomics, transcriptomics data and } \\
\text { bioinformatics tools }\end{array}$ & $\begin{array}{l}\text { Li et al. } \\
2016\end{array}$ \\
\hline $\operatorname{LIS}^{2)}$ & $\begin{array}{l}\text { Common bean, chickpea, pigeonpea, } \\
\text { Medicago truncatula, Lotus japonicus, } \\
\text { mungbean, soybean, and two Arachis } \\
\text { species }\end{array}$ & http://legumeinfo.org & $\begin{array}{l}\text { A resource for trait genetics and comparative } \\
\text { genomics for nine species of legumes } \\
\text { including }\end{array}$ & $\begin{array}{l}\text { Dash et al. } \\
2016\end{array}$ \\
\hline FragariaCyc & Strawberry & $\begin{array}{l}\text { http://pathways.cgrb. } \\
\text { oregonstate.edu/pgd } \\
\text { b/fragariacyc.shtml }\end{array}$ & $\begin{array}{l}\text { A metabolic pathway network for diploid } \\
\text { strawberry Fragaria vesca }\end{array}$ & $\begin{array}{l}\text { Naithani } \\
\text { et al. } \\
2016 \mathrm{~b}\end{array}$ \\
\hline $\begin{array}{l}\text { Intronless Genes } \\
\text { Database }\end{array}$ & $\begin{array}{l}\text { Sorghum bicolor, Zea mays, Setaria italica, } \\
\text { Panicum virgatum and Brachypodium } \\
\text { distachyon }\end{array}$ & $\begin{array}{l}\text { http://pigd.ahau.edu. } \\
\mathrm{cn} /\end{array}$ & A database for intronless genes in the Poaceae & Fan 2016 \\
\hline Phytozome & Plants & $\begin{array}{l}\text { http://www.phytozo } \\
\text { me.net }\end{array}$ & Gene family construction and analysis & $\begin{array}{l}\text { Phillips } \\
\text { et al. } 2016\end{array}$ \\
\hline $\begin{array}{l}\text { Plant Omics } \\
\text { Data Center }\end{array}$ & $\begin{array}{l}\text { Nicotiana tabacum, Zea mays, Arabidopsis } \\
\text { thaliana, Solanum lycopersicum, Solanum } \\
\text { tuberosum, Oryza sativa, Sorghum } \\
\text { bicolor, Vitis vinifera, Medicago } \\
\text { truncatula, and Glycine max }\end{array}$ & $\begin{array}{l}\text { http://bioinf.mind.me } \\
\text { iji.ac.jp/pode/ }\end{array}$ & $\begin{array}{l}\text { An integrated web repository for interspecies } \\
\text { gene expression networks with NLP-based } \\
\text { curation }\end{array}$ & $\begin{array}{l}\text { Terashima } \\
\text { et al. } 2016\end{array}$ \\
\hline Planteome initiative & Plants & $\begin{array}{l}\text { http://www.planteom } \\
\text { e.org }\end{array}$ & $\begin{array}{l}\text { A resource for common reference ontologies } \\
\text { and applications for plant biology }\end{array}$ & $\begin{array}{l}\text { Jaiswal } \\
\text { et al. } 2016 \mathrm{a}\end{array}$ \\
\hline $\begin{array}{l}\text { Online Resource for } \\
\text { Community } \\
\text { Annotation of } \\
\text { Eukaryotes }\end{array}$ & Eukaryotes & $\begin{array}{l}\text { http://bioinformatics. } \\
\text { psb.ugent.be/orcae/ }\end{array}$ & $\begin{array}{l}\text { Online resource for community annotation of } \\
\text { Eukaryotes }\end{array}$ & $\begin{array}{l}\text { Sterck et al. } \\
2016\end{array}$ \\
\hline GSP & Polyploids & $\begin{array}{l}\text { http://probes.pw.usda. } \\
\text { gov/GSP }\end{array}$ & $\begin{array}{l}\text { A web-based platform for designing } \\
\text { genome-specific primers in polyploids }\end{array}$ & $\begin{array}{l}\text { Gu et al. } \\
2016\end{array}$ \\
\hline
\end{tabular}

${ }^{2)}$ LIS: legume information system; GSP: genome-specific primers; SRA: sequence read archive; QTL: quantitative trait loci; NLP: natural language programming. 
productivity and biomass increase that were introduced in PAG XXIV. In addition, several useful databases were revealed in PAG XXIV. They were developed to integrate a growing set of commonly used data types and analysis tools with new capabilities for visualization, exploration, and predictive analysis (Table 1) (Cannon et al. 2016; Chan et al. 2016; Dai and Zhao 2016; Dash et al. 2016; Fan 2016; Gu et al. 2016; Humann et al. 2016; Ichihara et al. 2016; Jaiswal et al. 2016a, 2016b; Kersey 2016; Kodama et al. 2016; Kumari et al. 2016; Li et al. 2016; Mochizuki et al. 2016; Naithani et al. 2016a, 2016b; Phillips et al. 2016; Sterck et al. 2016; Terashima et al. 2016).

\section{FLOWERING TIME VS. BIOMASS}

Flowering time is one key factor that affects the biomass yield as delaying flowering time can prolong the period of vegetative growth, which in turn can increase the biomass. However, delayed flowering also increases susceptibility to winter mortality, thus decreasing productivity in following years. Therefore, understanding flowering time regulation in crops will be helpful to improve biomass yield. Genetic variations associated with flowering time and plant biomass have provided important bases for identifying quantitative trait loci (QTLs) in switchgrass (Panicum virgatum L.) that is important for cellulosic biofuel production (Taylor et al. 2016). To decipher natural allelic variations responsible for biomass yield and quality traits, a Nested Association Mapping population of switchgrass has been developed (Ali et al. 2016). Exome-capture genotyping over one million single nucleotide polymorphisms (SNPs) in switchgrass individuals has been used to identify their associations with heading date measured over three years (Grabowski et al. 2016). SNP variation studies have revealed a non-conservative amino acid substitution located in a protein-arginine deiminase domain in Phytochrome B (a photoperiod responsive gene) in correlation with flowering time phenotypes (Bahri et al. 2016).

The two major external stimuli used by temperate cereals to coordinate flowering are temperature and light through vernalization and photoperiod pathways (Shaw et al. 2016). These pathways converge on Flowering Locus T1 (FT1). FT belongs to small multigene phosphatidyl ethanolamine-binding protein (PEBP) family (Shaw et al. 2016). There are six FT-like members in wheat. While data suggests that FT1 is a key gene in the induction of flowering, its deletion has resulted in delayed flowering for less than one month, suggesting that other FT-like genes may have overlapping functions (Shaw et al. 2016). FT2 homologs have been characterized in temperate grass Brachypodium distachyon, barley, and wheat (Shaw et al. 2016). It has been found that FT2 is not essential for flowering. However, it does contribute to the promotion of flowering in both Brachypodium and wheat (Shaw et al. 2016). It was also found that $F T 2$ gene expression profiles are different from those of $F T 1$, suggesting that these two genes may have independent roles in the regulation of flowering in temperate cereals (Shaw et al. 2016).

Wheat cultivars exposed to optimal photoperiod and vernalization treatments still exhibit differences in heading time (Alvarez et al. 2016). This variation, known as earliness per se (Eps), is important for fine-tuning flowering time and the adaptation to different environments (Alvarez et al. 2016). It has been previously found that the $E p s-A^{m} I$ locus in Triticum monococcum can significantly delay flowering while increasing the number of spikelets per spike (Alvarez et al. 2016). However, wheat ortholog of circadian clock regulator EARLY FLOWERING 3 (ELF3) is different from the previous $E p s-A^{m} l$ allele in four amino acids associated with altered transcription profiles of PIF-like, PPD1, and FT1, the downstream targets of ELF3 (Alvarez et al. 2016).

FLOWERING LOCUS $M$ (FLM) has been recently described as an important regulator of ambient temperature-regulated flowering (Lutz 2016). It has been proposed that modulation of FLM abundance is an important mechanism for the adaptation of plants and flowering to changing ambient temperatures (Lutz 2016). Therefore, elucidating the genetic control of flowering time should help breeding efforts and the development of resources to enhance the adaptabilities and yield potentials of crops. 


\section{GRAIN YIELD}

Grain yield and quality traits are key contributors to the amount of usable energy available as food and feeds. High grain yield is one of the most important traits that require improvement in rice breeding programs. The genetic basis of spikelets per panicle (SPP) and grain weight (TGW) could be used to determine grain yield of rice. Both qSPP6 and $q T G W 6$ alleles are involved in the improvement of rice yields (Ahn et al. 2016). In addition, inflorescence architecture has been proposed as a key agronomical factor determining grain yield (Zhu and Sun 2016).

Wheat is one of the most important crops worldwide. In recent years, there has been significant interest in improving this crop to meet current and future global demands. Therefore, increasing sink strength of the spike is crucial for wheat breeding. Guo et al. (2016) have suggested that $V R N, P p d, F T, R h t$, and $Q$ genes are involved in the regulation of assimilate distribution among competing plant parts, supporting that manipulating assimilate partitioning is an important strategy to improve grain yield of wheat.

Bread wheat (T. aestivum) is an allohexaploid (AABBDD) with a large $(17 \mathrm{~Gb})$ genome. Mapping efforts have been underway for many years. Wheat breeders have considered grain protein concentration as the principal trait of interest to wheat producers. A genome-wide association study has found several putative loci associated with grain protein concentration on chromosomes 2A, 4A, and 2D (Dao et al. 2016). Whereas, several putative loci associated with test weight on chromosomes 1B, 2B, 3B, and 4B (Dao et al. 2016).

The starchy endosperm of wheat kernel is a major source of carbohydrates worldwide (Schönhofen et al. 2016). Starches with higher proportions of amylose will have higher content of resistant starch, a fermentable dietary fiber that can provide health benefits. A strategy to increase the levels of resistant starch is to pyramid mutations in STARCH BRANCHING ENZYME II (SBEII) isoforms $S B E I I a$ and SBEIIb in the three homoeologs present in A, $\mathrm{B}$, and $\mathrm{D}$ genomes of common wheat (Schönhofen et al. 2016). Quintuple mutant line (mutated SBEIIa/b in A and B genomes, and SBEIIa in D genome) has significant differences in starch viscosity parameters (Schönhofen $e t$ al. 2016). The release of common wheat germplasm combining five SBEII mutations is expected to expedite the development of varieties with increased amylose and resistant starch contents (Schönhofen et al. 2016). Thus, studies on compositional grain traits can help crop breeders to increase grain yield and improve grain quality.

\section{PHOTOSYNTHESIS VS. BIOMASS}

Different aspects of plant biomass provide important feedstocks for energy production, providing a promising solution to sustainable energy challenge in the 21 st century. Sugarcane has a C4-type of metabolism for carbon fixation, allowing it to produce enormous amounts of biomass in tropical and subtropical regions. Genetic improvement of photosynthetic efficiency can be theoretically achieved by targeting higher photosynthetic rates/unit of leaf area and by developing the most photosynthetically effective canopy (Kannan et al. 2016). Recent modeling work has indicated that the $\mathrm{C} 4$ photosynthetic machinery could be currently limited by inadequate pyruvate orthophosphate dikinase (PPDK) levels (Kannan et al. 2016). Field performance of transgenic sugarcane with reduced chlorophyll content, altered chloroplast size and elevated levels of PPDK has been examined using RNAi suppression of candidate genes to enhance light transmission into the canopy and PPDK level (Kannan et al. 2016).

Both leaf and seed starch biosynthesis are important for cereal crop yields. Carbohydrates are stored transiently as starch in leaves and as starch in seeds in long term (Oiestad et al. 2016). Adenosine diphosphate (ADP)-glucose pyrophosphorylase (AGP) is the rate-limiting step in starch biosynthesis (Oiestad et al. 2016). Enhanced rice growth and whole plant metabolism have been found to be conferred by increased leaf and seed AGP activity through overexpressing leaf and seed AGP (Oiestad et al. 2016). Artificial microRNA (amiR) strategy to silence NADP-malic enzyme family in Arabidopsis thaliana has been used to manipulate carbon flow to impact plant biomass (Paoli et al. 2016). Taken together, managing carbon flow within plant metabolism could improve 
different aspects of biomass feedstocks, thus advancing current plant capabilities for fiber and fuel production.

\section{LIGNIFICATION AND BIOMASS}

Ideal feedstock needs to produce biomass in high amounts while maintaining the quality. This is directly linked to cell wall composition (Yanagui et al. 2016). Energy cane is a high-biomass dedicated crop selected during the Saccharum breeding program to fit particular industrial needs of $2 \mathrm{G}$ bioethanol production (Yanagui et al. 2016). Transcriptional profile of elongating energy cane internode has revealed insights about vascular bundle lignification. The expression profiles of lignification genes have a gradient pattern, with higher expression in sections having complete lignified vascular bundles compared to sections without lignifications (Yanagui et al. 2016).

Grasses cover approximately $20 \%$ of terrestrial land provides $50 \%$ of human calories. When dried, secondary cell walls (SCW) are the bulk of grass biomass. Therefore, genome-scale network analysis has been used to identify rice $\mathrm{SCW}$ associated regulators that can control SCW biosynthesis in grasses to improve fuel, feed, and fiber production (Zhao et al. 2016).

\section{PLANT-ASSOCIATED MICROBES}

One approach in developing sustainable agriculture techniques is to utilize plant-associated microbes for plant growth promotion, biological nitrogen fixation, or biocontrol. Bacteria have been isolated from the rhizoplane and endophytic compartments of $A$. thaliana and the effect of these isolates on Setaria viridis plant health has been evaluated under various nutrient starvation stresses, especially phosphate starvation stress (Mucyn 2016). Symbiosis with microbial endophytes can enhance nitrogen fixation, confer drought tolerance, reduce reactive oxygen species, increase plant growth, and improve photosynthetic parameters during drought stress in hybrid poplars (Doty et al. 2016).

Populations of bacterial endophytes have been identified within Miscanthus that can be grown on low grade land with minimal requirements (Cope-Selby et al. 2016). The most diverse population of endophytes has been found in the seedling (Cope-Selby et al. 2016). Therefore, vertical transmission through seed has been suggested as an important process for sustaining bacterial endophytes in Miscanthus with potential of sustainable crop production (Cope-Selby et al. 2016).

\section{BIOTIC AND ABIOTIC STRESSES}

Exposure of crops to environmental stresses threatens agricultural sustainability (Hendrickson et al. 2016). Accordingly, new tools are needed to improve their tolerance to environmental stress to ensure long-term sustainability in crop production (Hendrickson et al. 2016). Alternative splicing (AS) of precursor messenger RNAs is a widespread phenomenon in plants. Approximately $42 \%$ to $61 \%$ of intron-containing genes exhibit AS (Filichkin et al. 2016). Differential intron retention has been identified as a key component in AS-driven adaptation to osmotic (dehydration or high salinity) and thermal stresses (heat or cold) in the transcriptome of western poplar (Populus trichcarpa) (Filichkin et al. 2016).

There are two major ecotypes of switchgrass: 1 ) the one originates from the lowland of the southern east coastal region of the Unites States, and 2) the one originates from the upland the northern regions of the United States. Late-flowering lowland varieties have the potential to be more productive than adapted upland varieties in the north. However, they are more susceptible to winter damage. Therefore, it would be desirable to combine the late-flowering lowland trait with the adaptation traits of upland varieties (Tornqvist et al. 2016). Lowland ecotypes are typically favorable due to their high biomass yield and tolerance to heat and drought. In some areas, the upland ecotypes are favored due to their adaptability to cold conditions. Genome wide methylated DNA immunoprecipitation-sequencing has revealed higher methylation level in AP13 of lowland than that in VS16 of upland (Crampton et al. 2016). Transcriptome analysis has identified genes involved in stress responses to drought, heat, flooding, 
salinity, or pathogen. RNA binding proteins, Mei2-like, pumilio, and RNA recognition motif (RRM) domain containing proteins have been implicated in posttranscriptional gene regulation (Fiedler et al. 2016).

Plants have an internal clock that mediates almost all daily activities and coordinates internal molecular responses with the environment. Interestingly, day-dependent responses to abiotic stress have been shown in Oryza sativa (Desai 2016).

Aquaporin $(A Q P)$ genes are responsible for water transportation in plants. Their functions are to transport water and nutrient molecules through living membranes. They might be essential for survival under salt and drought stresses. Differential expression profiles of 22 members of the BrPIP subfamily against biotic and abiotic stresses have provided a basis to elucidate stress-related biological functions of specific PIP genes in abiotic and biotic stress tolerance in Brassica rapa (Kayum et al. 2016).

Histone deacetylases (HDACs) are important regulators of chromatin structure and function (Hayford et al. 2016). HDACs have been found to play key roles in plant developmental processes (Hayford et al. 2016). They also respond to environmental cues (Hayford et al. 2016). For example, Arabidopsis $H D A 6$ can regulate transcription of ribosomal RNA and play a role in cold acclimation (Hayford et al. 2016). Up-regulation of HDA6 in common bean is age dependent (seedling $>$ flowering $>$ maturity). Spatial distribution analysis has revealed more HDA6 transcripts in flowers and pods. Accordingly, a crucial role of HDA6 in the growth and development of common beans has been proposed (Hayford et al. 2016). In addition, HDA6 also appears to be involved in cold response (Hayford et al. 2016).

TIFY family novel plant-specific group of genes have been widely reported for their important functions related to biological processes such as plant development and responses to stress and hormone in different crop species. A total of 36 TIFY genes have been characterized and classified under four subfamilies (JAZ, TIFY, ZML, and PPD) in B. rapa (Saha et al. 2016). Among them, nine $J A Z s$ have been shown to be differentially up-regulated against cold stress and jasmonic acid treatment (Saha et al. 2016). BrTIFY $3 a, 3 b, 6 a, 9 a, 9 b$, and $9 c$ have been shown to have corresponsive expression against salt, drought, Fusarium, ABA, and SA treatment, respectively (Saha et al. 2016).

One of the most severe pathogens that threaten wheat production worldwide is stripe rust caused by Puccinia striiformis f. sp. Tritici (Nazarov 2016). Genetic resistance to rust has been proven to be the most economically efficient method to control this pathogen (Nazarov 2016). High temperature adult plant resistance (HTAP) has been previously reported as a promising trait that can grant resistance to a broad range of stripe rust pathogens with high level of resistance, especially in warm climatic conditions (Nazarov 2016). A novel HTAP locus has been reported in wheat after performing further synteny analysis utilizing wheat SNP database followed by target amplifications and restriction essays, leading to the mapping of polymorphic marker of HTAP locus on the short arm of chromosome 2B (Nazarov 2016). In addition, the suppressor of rps4-RLD 1 (SRFR1) has been identified as a negative regulator of effector triggered immunity against bacterial pathogen Pseudomonas syringae pv (Nguyen et al. 2016). Recessive srfrl mutation in tomato has been found to be able to confer enhanced disease susceptibilityl (EDS1) dependent resistance to DC3000 (avrRps4) in Arabidopsis leaves (Nguyen et al. 2016). In addition, srfrl-1 plants have increased resistance to herbivory by beet army worm Spodoptera exigua and parasitism by cyst nematode Heterodera schachtii (Nguyen et al. 2016).

B. rapa cysteine protease $3(C P 3)$ is an endopeptidase member of C1A family (papain-like) and CA clan of cysteine protease (Niño et al. 2016). Members of papain-like $\mathrm{CP}$ have emerged to be key enzymes involved in cell death in response to biotic and environmental stresses (Niño et al. 2016). Regulation of rice resistance through cysteine protease activity is evident in overexpression lines of $\mathrm{BrCP} 3$ with enhanced immunity to three isolates of Xanthomonas oryzae pv. oryzae (Niño et al. 2015, 2016).

Remarkable projects in the area of crop stress tolerance presented at PAG XXIV could represent attractive initial points for functional characterization of plant genes. This will support future efforts to improve crop productivity during biotic and abiotic stresses. Some studies on abiotic stresses that could threaten crop productivity are discussed 
in the following sections.

\section{DROUGHT STRESS}

Climate models have predicted that a gradual increase in temperature and $\mathrm{CO}_{2}$ concentration can lead to the escalation of drought incidence and duration in many regions around the world (Tavakol 2016). Miscanthus, a genus of $\mathrm{C} 4$ perennial grasses, is of great interest for the production of biorenewable energy and chemicals due to its high biomass potential even in temperate regions (Malinowska et al. 2016). Yield of Miscanthus strongly depends on water availability. Many places across Europe where irrigation and temperature are favorable for Miscanthus cultivation with limited water supply. Therefore, the response of diverse genotypes of Miscanthus to reduce water availability has been investigated. This will help identify pathways responsible for drought resistance and sensitivity to improve selections of plants with good biomass production under water stress (Malinowska et al. 2016). A QTL ( $q D H Y .3 B L)$ located on chromosome 3BL has been found to be associated with increased grain and plant biomass under drought and heat stresses in bread wheat (Thomelin et al. 2016).

Uridine diphosphate (UDP)-glucose 4-epimerase (UGE) catalyzes the reversible conversion of UDP-glucose to UDP-galactose (Lee et al. 2016). A potential role of BrUGE1 in improving rice growth performance under optimal and water deficit conditions has been proposed. In addition, rice with $B r U G E 1$ overexpression has been shown to have enhanced tolerance to salt and bacterial infections caused by X. oryzae pv Oryzae (Lee et al. 2016).

Increased water soluble carbohydrate concentration in stem bases contributes withstable wheat grain yield under terminal water deficit (Ovenden 2016). Initial studies have indicated moderate broad sense heritability of this trait. However, molecular marker technologies could facilitate greater genetic gain for this complex trait. Water soluble carbohydrate accumulation is subjected to the dynamics of supply from photosynthesis and demand from maturing grains and other sinks. It is also influenced by phenology, plant size, stem diameter, and canopy senescence under the influence of declining water availability during grain fill. Thus, genetic contribution of water soluble carbohydrate concentration to yield has been studied in contrasting environmental conditions (Ovenden 2016).

Fructans are naturally occurring plant oligo- and polysaccharides composed of fructose molecules (Veenstra et al. 2016). These polymers are known as carbon stores with potential to protect plants against water deficit.

Utilizing materials from a multi-year multi-environment study, factors influencing variation of wheat grain fructan content in 289 winter wheat varieties have been examined (Veenstra et al. 2016). Information regarding the effect of genotype and environment on wheat grain fructan can be utilized to implement recurrent genomic selection in winter wheat and guide future decisions regarding breeding methodologies for total fructan content in wheat.

Post-anthesis drought is a common limiting factor for many temperate wheat growing regions including the USA (Babar et al. 2016). The most pronounced significant changes are in amino acids, sugars, and antioxidant compounds. Specifically, L-tyrosine, L-isoleucine, L-serine, L-aspertate，L-glutamate，3-hydroxy-3-methylglutarate, L-threonine, D-arabinose, and sedoheptulose are strongly expressed. They are potentially associated with drought tolerance in wheat (Babar et al. 2016). By comparing molecular, physiological, and compositional responses of plants to drought, we hope to identify pathways responsible for drought resistance and sensitivity so that we can improve selections for plants with good biomass production under water stress.

\section{CADMIUM}

Wheat ( $T$. aestivum L.) genotypes have different propensities to accumulate cadmium $(\mathrm{Cd})$ that is toxic. Producing low $\mathrm{Cd}$ grain is important for safe and healthy food supply. The maximum level of $\mathrm{Cd}$ concentration that is allowed to trade on international markets for wheat grain is $0.2 \mathrm{mg} / \mathrm{kg}$ (Oladzadabbasabadi et al. 2016). Therefore, accumulation of $\mathrm{Cd}$ in durum wheat (T. turgidum L. var. durum Desf) may threaten its export. Genetic mapping of SNP associated with low Cd uptake has been studied in 
durum wheat (Oladzadabbasabadi et al. 2016).

In field-grown plants, grain $\mathrm{Cd}$ concentration is proportional to above-ground plant $\mathrm{Cd}$ concentration at flowering (Guttieri et al. 2016). In low-volume hydroponic system, high-Cd wheat genotypes have been found to accumulate more $\mathrm{Cd}$ in shoots but less $\mathrm{Cd}$ in roots than low-Cd wheat genotype (Guttieri et al. 2016). It has been shown that Cd-upregulated transcripts include transcripts associated with metal ion binding, whereas Cd-downregulated transcripts are almost transcripts associated with nicotianamine biosynthetic processes (Guttieri et al. 2016). The transcript that responded differently to $\mathrm{Cd}$ was homologous to YS1, an iron-phytosiderophore transporter. It was downregulated in the Cd-accumulating genotype, together with the transcripts encoding a group of defense-related Mn-binding proteins that was upregulated in high-Cd genotype (Guttieri et al. 2016). In addition, a plant cadmium resistance 1 (PCRl) in rice has been found to be able to influence both zinc $(\mathrm{Zn})$ accumulation and weight of rice grain (Song et al. 2016). Interestingly, the grains of OSPCR 1 -knockdown lines of rice contain substantially more $\mathrm{Zn}$ and less $\mathrm{Cd}$ concentration than control rice (Song et al. 2016).

\section{ELEVATED OZONE CONCENTRATION}

Exposure to elevated ozone concentrations $\left[\mathrm{O}_{3}\right]$ can accelerate the rate of leaf senescence, thus decreasing the functional lifespan of leaves and reducing plant productivity. The natural molecular and biochemical components of senescence are accelerated at elevated $\left[\mathrm{O}_{3}\right]$, including upregulation of senescence associated genes, down-regulation of photosynthetic genes, degradation of chlorophyll, and loss of Rubisco protein activity (Ainsworth et al. 2016). Variation in $\left[\mathrm{O}_{3}\right]$-induced senescence has been reported to be correlated to yield losses in maize and wheat as well as rice (Ainsworth et al. 2016). The genotypic diversity in yield and grain quality responses to elevated ozone of diverse inbred and hybrid maize have been studied. It has been reported that yield loss is primarily driven by decreased kernel number on inbreds versus decreased individual kernel mass in hybrids (Rios-Acosta et al. 2016). Yield loss is also associated with increased kernel protein content under elevated $\left[\mathrm{O}_{3}\right]$ (Rios-Acosta et al. 2016).

\section{HERBICIDES}

Glyphosate, a leading broad spectrum herbicide, is toxic to rice (Cui et al. 2016). Therefore, developing glyphosateresistant rice can broaden available herbicides for rice production and provide more effective weed management strategies. A japonica rice transformed by Isoptericola variabilis-EPSPS*, a novel herbicide-resistant gene isolated from bacterium I. variabilis, has been found to be glyphosate-resistant. It can survive when the application dose of glyphosate is 10 times higher than the recommended dose for agricultural application (Cui et al. 2016).

Foxtail millet ( $S$. italica) is a nutritious plant. It is tolerant to drought and barren conditions. It is an important crop in northern China where there is severe water shortage (Cheng et al. 2016). However, foxtail millet is very sensitive to herbicide. Its 1,000-grain weight is only about $3.0 \mathrm{~g}$, making precise seeding difficult (Cheng et al. 2016). Traditional thinning seedling and weed control by hand have limited the scale of millet planting. Millet materials with resistance to Sethoxydim, Imazethapyr, and Nicosulfuron are controlled by a single dominant gene. They have been obtained by crossing Chinese cultivated millet varieties with green foxtail (S. viridis) herbicideresistant mutants coming from Canada since 1993. By crossing herbicide-susceptible male-sterile line with herbicide-resistant restoring line, self-crossed sterile line could be killed when herbicide is applied (Cheng et al. 2016). The application of herbicide resistant varieties and hybrids has overcome the obstacle of seedling thinning and weed control by hand in the field, leading to large-scale millet production in China for the first time (Cheng et al. 2016).

\section{FUSARIUM}

Fusarium head blight (FHB) caused by Fusarium 
graminearum Schwabe (Teleomorph: Gibberellazeae) is one of the most devastating diseases that severely affects crop production (Kumar and Kushalappa 2016). Resistance to FHB is highly complex and quantitative in nature (Kumar and Kushalappa 2016). Resistance to FHB can be classified as type-I (resistance to initial infection of spikelets) or type-II (resistance to spread within the spike or rachis resistance). Barley has high level of type-II resistance. It is reported that WIN1 transcription factor can channelize free fatty acids to enforce cuticle in barley spikelets to resist FHB (Kumar and Kushalappa 2016). Dhokane (2016) has dissected the second major QTL (QTL-Fhb2) that can impart rachis resistance (Type-II). Basic Helix Loop Helix (bHLH) transcription factor, 4-Coumarate-CoA Ligase ( $4 C L$ ), Glutathione S-transferase (GST), and $\mathrm{ABC}$ transporter have been found as putative candidate genes for QTL locus imparting resistance to FHB in wheat. In addition, the wild grass species Thinopyrum elongatum has been identified as a source of strong FHB resistance (Ouellet et al. 2016). Resistance to FHB has been mapped to the long arm of chromosome 7E in $T$. elongatum. This is of great interest because it can protect wheat against FHB to a high level. In addition, the source is located on a single chromosome arm, possibly at a single locus, in contrast to other sources of resistance that are complex and multi-genic. Thus, Ouellet et al. (2016) have developed approaches to characterize and clone the 7EL source of FHB resistance.

\section{GENOME METHODOLOGY} ADVANCEMENTS

Several novel high-throughput methods in the area of genome technology have been presented at PAG XXIV. Recent advances in genome sequencing and mapping methods, high quality library construction, phenotyping and genotyping technologies, targeted mutagenesis systems, genome amplifications, and genetic improvement approaches were revealed at PAG XXIV. In addition, DNA and RNA extraction kits as well as fast and reliable electrophoresis system that can empower molecular biologist to obtain high yield and high quantities of DNA with high performance and sensitive separation as well as analysis of DNA fragments were revealed at PAG XXIV. Moreover, FastMiR, an RNA-based sensor for in vitro detection of small RNA designated to revolutionize analyses of small RNAs (21- to 24-nucleotide molecules, including microRNAs (miRNAs) and small interfering RNAs (siRNAs) has been reported (Huang et al. 2016). It will shed light on the regulatory roles of small RNAs and miRNAs in plants and animals (Huang et al. 2016).

\section{MALE STERILITY AND BREEDING}

Male sterility is an important trait. It plays a key role in hybrid breeding in crops. Thermo-sensitive genic male sterility (TGMS) lines that are male-sterile at high temperatures but can be converted to male-fertile at low temperatures have been widely used in two-line hybrid rice breeding. A rice (O. sativa L.) thermo-sensitive genic male sterile gene 5 (tms5) locus has been found to confer the TGMS trait through a loss-of-function mutation of RNase $Z^{S l}$ belonging to the metallo- $\beta$-lactamase superfamily. The loss-of-function mutation of RNase $Z^{S l}$ can result in failing to mediate the mRNA decay of UbiL40, a temperatureresponsive ubiquitin-encoding gene family, finally causing over-accumulation of mRNAs in young anthers at high temperatures (Zhou et al. 2016). In addition, VoltageDependent Anion Channel (VDAC) gene family has been found to be involved in the formation of HonglianCytoplasmic Male Sterility in rice (Xu et al. 2016).

\section{CROP DOMESTICATION}

Cultivated rice $O$. sativa $\mathrm{L}$. originated from tropical regions is now grown worldwide due to concerted efforts of breeding programs. Through the domestication process, many traits from wild rice are lost, including awn phenotype (the elongated spine-like organ at the tip of seeds), functions in seed dispersal, and preventing predation by animals. Therefore, genes responsible for awn development have been identified in rice with possible correlation with the domestication process (Uehara 2016). 


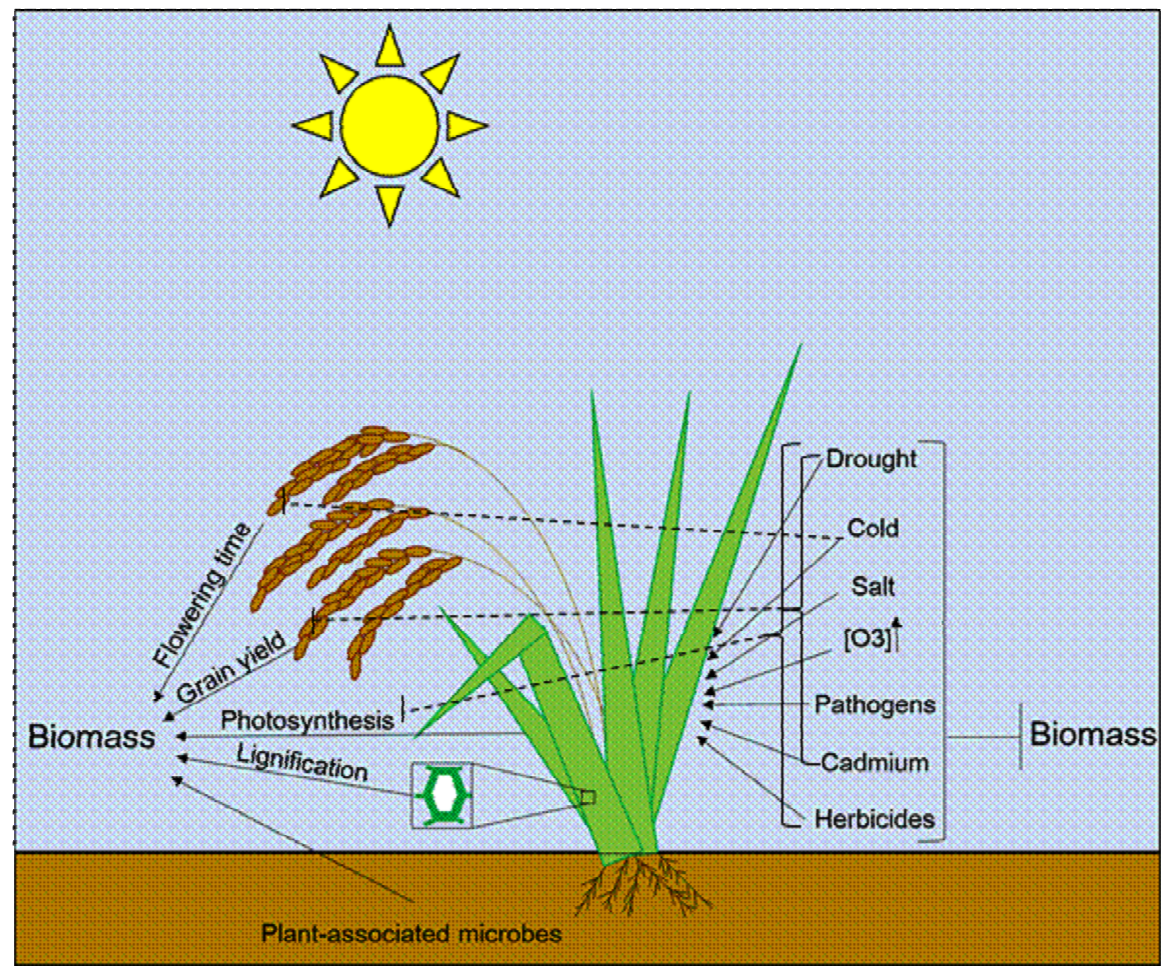

Fig. 1. Schematic representation of factors that can positively and negatively affect crop biomass.

The transition from a spread panicle typical of ancestral wild rice (O. rufipogon Griff.) to the compact panicle of present cultivars (O. sativa L.) is a crucial event in rice domestication. In this case, a SNP6 residing in the regulatory region $11 \mathrm{~kb}$ upstream of the spread panicle architecture gene Panicle Architecture Control 1 (PAC1)/ $L G 1$ (laminar joint and ligule development gene) can lead to a compact panicle architecture in cultivars during rice domestication (Zhu and Sun 2016). Therefore, rice inflorescence architecture can be suggested as a major target of rice domestication.

Loss or reduction of hard seededness or impermeability water is a key step that can lead to domestication of many leguminous crops for agricultural production (Sun 2016). Map-based cloning and characterization studies have revealed that a major QTL designated as $H_{s} 1$ can control the seed hardedness in Glycine soja. Hsl encodes a calcineurin-like metallo-phosphoesterase-like transmembrane protein localized in cellular membranes (Sun 2016). The transition from hard seededness in the wild accessions to soft seededness in cultivated soybeans is caused by a single nucleotide mutation within $H_{s} 1$, resulting in an amino acid change and a recessive mutation allele $(h s l)$ (Sun 2016).

\section{CONCLUSION}

We propose a model to elucidate factors that may positively or negatively affect the biomass of crops such as rice (Fig. 1). Further investigation on important yield traits contributing to increased biomassproduction and stress tolerance mechanisms will provide valuable data to improve our understanding on factors that may impact yield production. It will possibly help breeders to manipulate crop biomass accumulation.

\section{ACKNOWLEDGEMENTS}

This work was supported by a grant (2014R1A 2A1A11052547) of the National Research Foundation 
(NRF) program funded by the Ministry of Science, ICT and Future Planning, Republic of Korea.

\section{REFERENCES}

Ahn SN, Kim DM, Lee HS, Kang JW, Yu YT. 2016. High-density mapping reveals a linkage of quantitative trait loci for grain-weight and spikelet number in rice. Proc. of the Plant and Animal Genome Conference (PAG XXIV). San Diego, CA, USA. P0728.

Ainsworth EA, Burroughs C, Erice G, Montes CM, Shim SI, Wedow J, et al. 2016. Phenotyping genetic diversity in acceleration of maize leaf senescence under elevated ozone. Proc. of the Plant and Animal Genome Conference (PAG XXIV). San Diego, CA, USA. P0760.

Ali S, Chang J, Serba DD, Bhandari HS, Bartley L, Saha MC. 2016. Cataloging natural allelic variations in switchgrass (Panicum virgatum L.) NAM parental genomes. Proc. of the Plant and Animal Genome Conference (PAG XXIV). San Diego, CA, USA. P0012.

Alvarez MA, Tranquilli G, Lewis S, Kippes N, Dubcovsky J. 2016. Genetic and physical mapping of the earliness per se locus EpsAm1 in Triticum monococcum identifies EARLY FLOWERING 3 (ELF3) as a candidate gene. Proc. of the Plant and Animal Genome Conference (PAG XXIV). San Diego, CA, USA. P0843.

Babar M, Akond M, Beecher C, Jong F, Erickson J, Thomson K. 2016. Global metabolic expression in wheat under post-anthesis water stress conditions. Proc. of the Plant and Animal Genome Conference (PAG XXIV). San Diego, CA, USA. P0852.

Bahri BA, Daverdin G, Cheng JF, Barry KW, Devos KM. 2016. Single nucleotide polymorphism (SNP) variation in switchgrass (Panicum virgatum) for genes involved in biomass production. Proc. of the Plant and Animal Genome Conference (PAG XXIV). San Diego, CA, USA. P0013.

Cannon E, Huang W, Dash S, Singh J, Kalberer SR, Ren L, et al. 2016. PeanutBase: a resource for peanut researchers and breeders. Proc. of the Plant and Animal Genome Conference (PAG XXIV). San Diego, CA, USA. P0329.

Chan AP, Krishnakumar V, Cheng CY, Belyaeva I, Contrino S, Ferlanti E, et al. 2016. Araport - a community platform for data sharing, discovery and integration. Proc. of the
Plant and Animal Genome Conference (PAG XXIV). San Diego, CA, USA. P0286.

Cheng R, Liu G, Shi Z, Xia X, Zhang T. 2016. Application of herbicide-resistant genes from green foxtail millet in foxtail millet breeding. Proc. of the Plant and Animal Genome Conference (PAG XXIV). San Diego, CA, USA. W858.

Cope-Selby N, Smith D, Cookson A, Donnison I, Flavell R, Farrar K. 2016. Seed transmission of bacterial endophytes in Miscanthus. Proc. of the Plant and Animal Genome Conference (PAG XXIV). San Diego, CA, USA. P0011.

Crampton MC, Sripathi VR, Ayyappan V, Saha MC, Kalavacharla VK. 2016. Comparison of AP13 and VS16 switchgrass (Panicum virgatum) methylomes using highthroughput sequencing. Proc. of the Plant and Animal Genome Conference (PAG XXIV). San Diego, CA, USA. P0014.

Cui Y, Yi S, Liu Z, Chen H, Zhou F, Lin Y. 2016. Developing herbicide-resistant rice with novel genes. Proc. of the Plant and Animal Genome Conference (PAG XXIV). San Diego, CA, USA. P0741.

Dai X, Zhao PX. 2016. HRGRN: Model and decipher Arabidopsis signaling transduction, metabolism and gene regulation networks using graph theory. Proc. of the Plant and Animal Genome Conference (PAG XXIV). San Diego, CA, USA. P0332.

Dao HQ, Reid S, Harrington J, Byrne P. 2016. Genome-Wide Association Study in bread wheat identifies loci for grain protein concentration and test weight. Proc. of the Plant and Animal Genome Conference (PAG XXIV). San Diego, CA, USA. P0834.

Dash S, Huang W, Campbell JD, Singh J, Rice AG, Umale PE, et al. 2016. LIS (Legume Information System): a clade based web resource for legumes. Proc. of the Plant and Animal Genome Conference (PAG XXIV). San Diego, CA, USA. P0325.

Desai J. 2016. Time of day analysis of plant responses to abiotic stress. Proc. of the Plant and Animal Genome Conference (PAG XXIV). San Diego, CA, USA. P0033.

Dhokane D. 2016. Identification of Fusarium head blight resistance genes from wheat QTL-Fhb2, through forward and reverse genetics. Proc. of the Plant and Animal Genome Conference (PAG XXIV). San Diego, CA, USA. P0138.

Doty SL, Sher AW, Khan Z, Fleck ND, Firrincieli A, DeLuca 
TH, et al. 2016. Sustainable biomass production using plant growth promoting microbial endophytes. Proc. of the Plant and Animal Genome Conference (PAG XXIV). San Diego, CA, USA. P0026.

Fan J. 2016. PIGD: a database for intronless genes in the Poaceae. Proc. of the Plant and Animal Genome Conference (PAG XXIV). San Diego, CA, USA. P0316. Fiedler E, Ayyappan V, Sripathi VR, Saha MC, Thimmapuram J, Bhide K, et al. 2016. Transcriptome analysis of two switchgrass ecotypes: AP13 (lowland) and VS16 (upland). Proc. of the Plant and Animal Genome Conference (PAG XXIV). San Diego, CA, USA. P0017.

Filichkin S, Hamilton M, Dharmawardhana P, Ben-Hur A, Reddy A, Jaiswal P. 2016. Differential intron retention is a key component of alternative splicing-driven adaptation to abiotic stress in transcriptome of Western Poplar (Populus trichcarpa). Proc. of the Plant and Animal Genome Conference (PAG XXIV). San Diego, CA, USA. P0020.

Grabowski P, Evans J, Ramstein GP, Crisovan E, Vaillancourt B, Costich D, et al. 2016. Genome-Wide Associations with flowering time in switchgrass. Proc. of the Plant and Animal Genome Conference (PAG XXIV). San Diego, CA, USA. P0001.

Gu YQ, Wang Y, Tiwari VK, Rawat N, Gill BS, Huo N, et al. 2016. GSP: a web-based platform for designing genome-specific primers in polyploids. Proc. of the Plant and Animal Genome Conference (PAG XXIV). San Diego, CA, USA. P0305.

Guo Z, Chen D, Ganal MW, Röder MS, Schnurbusch T. 2016. Genetic determinants of grain yield in wheat revealed by assimilate partitioning. Proc. of the Plant and Animal Genome Conference (PAG XXIV). San Diego, CA, USA. P0832.

Guttieri MJ, Baenziger PS, Amundsen K, Waters BM. 2016. Variation in wheat root transcriptome response to cadmium. Proc. of the Plant and Animal Genome Conference (PAG XXIV). San Diego, CA, USA. P0856.

Hayford R, Osena A, Brown A, Melmaiee K, Hossain KG, Kalavacharla VK. 2016. Possible role of common bean (Phaseolus vulgaris L.) histone deacetylase6 in development and cold stress response. Proc. of the Plant and Animal Genome Conference (PAG XXIV). San Diego, CA, USA. P1009.

Hendrickson C, Kjelgren R, Dhingra A. 2016. Sporobolus spp. as resources for crop improvement in Poaceae. Proc. of the Plant and Animal Genome Conference (PAG XXIV). San Diego, CA, USA. P0429.

Huang K, Doyle F, Wurz ZE, Tenenbaum SA, Caplan JL, Meyers BC. 2016. FastMiR: An RNA-based sensor for in vitro detection of small RNA. Proc. of the Plant and Animal Genome Conference (PAG XXIV). San Diego, CA, USA. P0027.

Humann JL, Jung S, Zheng P, Cheng CH, Lee T, Frank M, et al. 2016. Cool season food legume genome database: an up-to-date resource enabling genetics, genomics and breeding research in Pea, Lentil, Faba Bean and Chickpea. Proc. of the Plant and Animal Genome Conference (PAG XXIV). San Diego, CA, USA. P0327.

Ichihara H, Shirasawa S, Shibaya T, Nakamura Y, Nakaya A, Kikuchi M, et al. 2016. Plant Genome Database Japan (PGDBj) in 2016: a comprehensive database covering information of plant genome-related database in Japan. Proc. of the Plant and Animal Genome Conference (PAG XXIV). San Diego, CA, USA. P0292.

Jaiswal P, Cooper L, Elser JL, Meier A, Laporte MA, Mungall C, et al. 2016a. Planteome: a resource for common reference ontologies and applications for plant biology. Proc. of the Plant and Animal Genome Conference (PAGXXIV). San Diego, CA, USA. P0312.

Jaiswal P, Preece J, D'Eustachio P, Naithani S, Elser JL, Mundo AF, et al. 2016b. Plant Reactome: A resource for comparative plant pathway analysis. Proc. of the Plant and Animal Genome Conference (PAGXXIV). San Diego, CA, USA. P0030.

Kannan B, Karan R, Grennan A, Jaikumar NS, Vilarinho A, Zhang X, et al. 2016. Field performance of transgenic sugarcane with reduced chlorophyll content, altered chloroplast size and elevated levels of PPDK. Proc. of the Plant and Animal Genome Conference (PAG XXIV). San Diego, CA, USA. P0022.

Kayum A, Han J, Park JI, Ahmed NU, Kang KK, Nou I. 2016. Role of Aquaporin gene family towards abiotic and biotic stress tolerance in Brassica rapa. Proc. of the Plant and Animal Genome Conference (PAG XXIV). San Diego, CA, USA. P0955.

Kersey PJ. 2016. Ensembl Genomes: genomic resources for plants, pests, pathogens and pollinators. Proc. of the Plant and Animal Genome Conference (PAG XXIV). San Diego, CA, USA. P0289. 
Kodama Y, Mashima J, Kaminuma E, Ogasawara O, Okubo K, Nakamura Y, et al. 2016. Database resources of DNA data bank of Japan. Proc. of the Plant and Animal Genome Conference (PAG XXIV). San Diego, CA, USA. P0291.

Kumar A, Kushalappa AC. 2016. WIN1 transcription factor channelizes free fatty acids to enforce cuticle in barley spikelets to resist Fusarium head blight. Proc. of the Plant and Animal Genome Conference (PAG XXIV). San Diego, CA, USA. P0044

Kumari S, Ware D, Weston D, Kumar V, Ramakrishnan S, Ranjan P, et al. 2016. The DOE systems biology knowledgebase (KBase): progress towards advanced modeling of sustainable bioenergy crop development. Proc. of the Plant and Animal Genome Conference (PAG XXIV). San Diego, CA, USA. P0002.

Lee HJ, Abdula SE, Kim J, Niño MC, Jung YJ, Cho YC, et al. 2016. BrUGE1 transgenic rice showed improved growth performance with enhanced drought tolerance. Proc. of the Plant and Animal Genome Conference (PAG XXIV). San Diego, CA, USA. P0126.

Li J, Dai X, Zhuang Z, Zhao PX. 2016. The LegumeIP (2016 Release) - a web-Based comparative genomics and gene expression atlas platform for the study of gene function and genome evolution in legumes. Proc. of the Plant and Animal Genome Conference (PAG XXIV). San Diego, CA, USA. P0326.

Lutz U. 2016. Temperature-dependent flowering of Arabidopsis thaliana is modulated by natural variation of Flowering Locus M. Proc. of the Plant and Animal Genome Conference (PAG XXIV). San Diego, CA, USA. W086.

Malinowska M, Vendramin V, Scalabrin S, Schnabel S, Donnison I, Robson PRH. 2016. Physiological and molecular analysis of drought stress responses in Miscanthus: identifying important traits for biofuel production from analysis of networks. Proc. of the Plant and Animal Genome Conference (PAG XXIV). San Diego, CA, USA. W086.

Mochizuki T, Tanizawa Y, Fujisawa T, Nikoh N, Shimizu T, Toyoda A, et al. 2016. DNA polymorphism annotation database (DNApod): toward an integration of SRA-driven genotypic data and public phenotypic data. Proc. of the Plant and Animal Genome Conference (PAG XXIV). San Diego, CA, USA. P0300.
Mucyn TS. 2016. Harvesting the root microbiome of grasses toward sustainable increase crop production. Proc. of the Plant and Animal Genome Conference (PAG XXIV). San Diego, CA, USA. P0007.

Naithani S, Partipilo C, Mohanty B, Lee DY, Jaiswal P. 2016a. Rice stress-response gene-network: an example of community curation in WikiPathways for plants. Proc. of the Plant and Animal Genome Conference (PAGXXIV). San Diego, CA, USA. P0032.

Naithani S, Partipilo C, Raja R, Elser JL, Jaiswal P. 2016b. FragariaCyc: a metabolic pathway network for diploid strawberry $F$. vesca. Proc. of the Plant and Animal Genome Conference (PAGXXIV). San Diego, CA, USA. P0324.

Nazarov T. 2016. Physical mapping of new High Temperature Adult Plant Resistance (HTAP) locus in wheat cultivar Louise. Proc. of the Plant and Animal Genome Conference (PAGXXIV). San Diego, CA, USA. P0848.

Nguyen PD, Pike S, Schultz J, Koo AJ, Mitchum MG, Appel $\mathrm{H}$, et al. 2016. Arabidopsis SRFR1 dampens defenses against herbivory by Spodoptera exigua and parasitism by Heterodera schachtii. Proc. of the Plant and Animal Genome Conference (PAG XXIV). San Diego, CA, USA. P0060.

Niño MC, Lee HJ, Kim J, Abdula SE, Jung YJ, Kang KK, et al. 2015. Enhancement of rice resistance to bacterial blight by overexpressing $\mathrm{BrCP} 3$ gene of Brassica rapa. Plant Breed. Biotech. 3: 355-365.

Niño MC, Lee HJ, Kim J, Abdula SE, Jung YJ, Kang KK, et al. 2016. Enhancement of rice resistance to bacterial blight by overexpressing $\mathrm{BrCP} 3$ gene of Brassica rapa. Proc. of the Plant and Animal Genome Conference (PAG XXIV). San Diego, CA, USA. P0135.

Oiestad AJ, Martin JM, Beecher BS, Giroux M. 2016. Enhanced rice growth and whole plant metabolism is conferred by increased leaf and seed ADP-glucose pyrophosphorylase activity. Proc. of the Plant and Animal Genome Conference (PAG XXIV). San Diego, CA, USA. P0034.

Oladzadabbasabadi A, Salsman E, Dobridina M, Chao S, Elias E. 2016. Genetic mapping of single nucleotide polymorphism (SNP) associated with low cadmium uptake in durum wheat (Triticum turgidum L. var. durum Desf.). Proc. of the Plant and Animal Genome Conference 
(PAG XXIV). San Diego, CA, USA. P0889.

Ouellet T, Gou L, Konkin D, Hattori J, Tekieh F, Wolfe D, et al. 2016. Towards cloning of the Fusarium head blight-resistance locus from Thinopyrum elongatum chromosome 7EL. Proc. of the Plant and Animal Genome Conference (PAG XXIV). San Diego, CA, USA. P0859.

Ovenden B, Milgate A, Rebetzke G, Wade L, Holland JB. 2016. Selection strategies for increasing water soluble carbohydrate accumulation in wheat. Proc. of the Plant and Animal Genome Conference (PAG XXIV). San Diego, CA, USA. P0838.

Paoli HCD, Engle N, Tschaplinski TJ, Abraham PE, Hettich RL, Mewalal R, et al. 2016. Rechanneling carbon flow with potential to increase valuable biomass feedstocks. Proc. of the Plant and Animal Genome Conference (PAG XXIV). San Diego, CA, USA. P0005.

Phillips JL, Carlson JW, Batra S, Goodstein DM, Rokhsar DS. 2016. Gene family construction and analysis in phytozome. Proc. of the Plant and Animal Genome Conference (PAG XXIV). San Diego, CA, USA. P0314.

Rios-Acosta L, Erice G, Kendzior MC, Lewis M, Mulcrone J, Goizueta IR, et al. 2016. Genotypic diversity in yield and grain quality responses to elevated ozone of diverse inbred and hybrid maize. Proc. of the Plant and Animal Genome Conference (PAG XXIV). San Diego, CA, USA. P0761.

Sade N, Wilhelmi MR, Souza WD, Wright M, Bassil E, Liu L, et al. 2016. Modifications of source-sink relationships and the development of stress-tolerant brachypodium. Proc. of the Plant and Animal Genome Conference (PAG XXIV). San Diego, CA, USA. W098.

Saha G, Park JI, Cho YG, Nou I. 2016. Molecular characterization and stress induced expression profiling of TIFY family genes in Chinese cabbage (Brassica rapa ssp. pekinensis). Proc. of the Plant and Animal Genome Conference (PAG XXIV). San Diego, CA, USA. P0957.

Schönhofen A, Hazard B, Zhang X, Dubcovsk J. 2016. Increased grain amylose and resistant starch in a quintuple SBEII-mutant common wheat. Proc. of the Plant and Animal Genome Conference (PAG XXIV). San Diego, CA, USA. P0835.

Shaw L, Lv B, Nitcher R, Li C, Han X, Fu D, et al. 2016. Characterization of Flowering Locus T2 (FT2) in wheat and brachypodium. Proc. of the Plant and Animal Genome Conference (PAG XXIV). San Diego, CA,
USA. P0837.

Song WY, Lee HS, Ahn SN, An G, Lee Y. 2016. Rice PCR1 influences grain weight and $\mathrm{Zn}$ accumulation in grains. Proc. of the Plant and Animal Genome Conference (PAG XXIV). San Diego, CA, USA. P0730.

Sterck L, Rombauts S, Rouzé P, Peer YV. 2016. ORCAE: online resource for community annotation of eukaryotes. Proc. of the Plant and Animal Genome Conference (PAG XXIV). San Diego, CA, USA. P0309.

Sun L. 2016. Artificial selection of seed-coat permeability during domestication: the desirable accompanied by the undesirable. Proc. of the Plant and Animal Genome Conference (PAG XXIV). San Diego, CA, USA. P0976.

Tavakol E. 2016. Genome-wide expression profiling of barley in response to drought stress under different potassium application levels. Proc. of the Plant and Animal Genome Conference (PAG XXIV). San Diego, CA, USA. P0141.

Taylor MS, Tornqvist CEI, Grabowski P, Casler M, Jiang Y. 2016. Genetic variation of flowering time and biomass in switchgrass. Proc. of the Plant and Animal Genome Conference (PAG XXIV). San Diego, CA, USA. P0016.

Terashima S, Kudo T, Takano T, Kanno M, Saito M, Matsuda $\mathrm{N}$, et al. 2016. Plant Omics Data Center: an integrated web repository for interspecies gene expression networks with NLP-based curation. Proc. of the Plant and Animal Genome Conference (PAG XXIV). San Diego, CA, USA. P0313.

Thomelin PML, Bonneau J, Taylor JD, Choulet F, Sourdille P, Langridge $\mathrm{P}$, et al. 2016. Positional cloning of a QTL, qDHY.3BL, on chromosome 3BL for drought and heat tolerance in bread wheat. Proc. of the Plant and Animal Genome Conference (PAG XXIV). San Diego, CA, USA. P0850.

Tornqvist CE, Ramstein GP, Evans J, Vaillancourt B, Crisovan E, Taylor MS, et al. 2016. Genetic analysis of flowering time in switchgrass using a pseudo-F2 population from an upland $\mathrm{x}$ lowland cross. Proc. of the Plant and Animal Genome Conference (PAG XXIV). San Diego, CA, USA. P0015.

Uehara K. 2016. Identification of responsible genes involved in awn development and discussion about rice domestication process. Proc. of the Plant and Animal Genome Conference (PAG XXIV). San Diego, CA, USA. P0726. 
Veenstra LD, Sorrells ME, Jannink JL. 2016. Influence of genotype and environment on wheat grain fructan content. Proc. of the Plant and Animal Genome Conference (PAG XXIV). San Diego, CA, USA. P0839.

Xu X, Tan Y, Qin Y, Cheng G, Wang C. 2016. The voltage-dependent anion channel (VDAC) gene family is involved in the formation of Honglian(HL)- Cytoplasmic Male Sterility (CMS) in rice. Proc. of the Plant and Animal Genome Conference (PAG XXIV). San Diego, CA, USA. P0036.

Yanagui K, Camargo ELO, Nagamatsu ST, Franco SF, Nascimento LC, Bressiani JA, et al. 2016. Transcriptional profile of elongating energy cane internode reveals insights through vascular bundle lignification. Proc. of the Plant and Animal Genome Conference (PAG XXIV). San
Diego, CA, USA. P0023.

Zhao K, Lin F, Saha P, Goh HJ, An G, Jung KH, et al. 2016. Identification of Rice secondary cell wall associated regulators via genome-scale network analysis. Proc. of the Plant and Animal Genome Conference (PAG XXIV). San Diego, CA, USA. P0035.

Zhou H, Li J, Zhu L, Jiang D, Dong J, Liu Q, et al. 2016. RNase ZS1 mediates UbL40 mRNAs decay controlling thermo-sensitive genic male sterility in rice. Proc. of the Plant and Animal Genome Conference (PAG XXIV). San Diego, CA, USA. P0737.

Zhu Z, Sun C. 2016. Genetic control of inflorescence architecture during rice domestication. Proc. of the Plant and Animal Genome Conference (PAG XXIV). San Diego, CA, USA. P0731. 